\title{
A CONTRIBUIÇÃo DA CONTROLADORIA PARA O SETOR PÚBLICO COMO APORTE PARA UMA GESTÃO MAIS EFICIENTE
}

\author{
THE CONTRIBUTION OF CONTROLLERSHIP TO THE PUBLIC SECTOR AS A AID \\ TO A MORE EFFICIENT MANAGEMENT
}

\author{
Fernanda Helena Cearense Paiva ${ }^{\mathrm{I}}$ \\ Josiane Ramos de Souza ${ }^{\text {II }}$ \\ Rosana Ribeiro III \\ Cassia Regina Bianchini Teixeira ${ }^{\text {IV }}$ \\ Alessandre Silva ${ }^{\mathrm{V}}$
}

\begin{abstract}
RESUMO
A controladoria pública exerce uma atividade econômica, financeira, orçamentária e patrimonial nas esferas da União, Estados, Distrito Federal e Municípios. Ela também pode ser entendida como uma ferramenta fundamental para o setor público, reunindo procedimentos e técnicas que buscam auxiliar a gestão pública. O presente trabalho busca investigar como a controladoria pública pode contribuir com uma gestão mais eficiente dos recursos públicos municipais, evidenciando suas vantagens para a sociedade e para os gestores públicos. A metodologia utilizada para atingir o objetivo proposto foi à pesquisa bibliográfica e documental, do tipo descritiva-exploratória, de cunho qualitativo. Para a coleta de dados, foram utilizadas obras didáticas, legislações, artigos científicos, revistas científicas especializadas e bases de dados científicas. Constatou-se ao longo da pesquisa que as empresas públicas que possuem o departamento de controladoria aumentam sua eficiência, melhorando a alocação de recursos, detectando-se um aumento da transparência em relação às decisões do gestor público e também em relação à prestação de contas, possibilitando a toda sociedade obter informações de forma mais clara e objetiva. Conclui-se que a controladoria no setor público é algo relativamente novo, que ainda precisa melhorar e, em muitos casos, a implementação ainda precisa ser concluída. Dentro dos casos de implementação concluídos, os resultados obtidos condizem com os aspectos apontados pela literatura, podendo ser percebida uma melhora nos quesitos gestão, transparência e prestação de contas, o que possibilita a todo e qualquer interessado acesso a informações consolidadas.
\end{abstract}

Palavras-chave: Controladoria do setor público. Transparência. Prestação de Contas.

I Bacharel em Ciências Contábeis, Faculdade de Ribeirão Preto - Grupo Universidade Brasil -São Paulo - Brasil. E-mail:. fernanda.helena.paiva@gmail.com

II Bacharel em Ciências Contábeis, Faculdade de Ribeirão Preto - Grupo Universidade Brasil -São Paulo - Brasil. E-mail: josiane.ramos.souza@gmail.com

III Bacharel em Ciências Contábeis, Faculdade de Ribeirão Preto - Grupo Universidade Brasil -São Paulo Brasil. E-mail:. rosana.ribeiro2018@gmail.com

IV Profa. Me. da Faculdade de Ribeirão Preto - Grupo Universidade Brasil-São Paulo-Brasil. E-mail: bianchinicr@yahoo.com.br

V Diretor, Coordenador, Prof. Me. da Faculdade de Ribeirão Preto - Grupo Universidade Brasil - São Paulo Brasil. E-mail: alessandre.silva@uniesp.edu.br 


\begin{abstract}
The public controllership carries out an economic, financial, budgetary and patrimonial activity in the spheres of the Union, States, Federal District and Municipalities. It can also be understood as a fundamental tool for the public sector, bringing together procedures and techniques that seek to assist public management. The present work seeks to investigate how public controllership can contribute to a more efficient management of municipal public resources, showing its advantages for society and for public managers. The methodology used to reach the proposed objective was to the bibliographic and documentary research, of the descriptive-exploratory type, of qualitative character. For data collection, didactic works, legislation, scientific articles, specialized scientific journals and scientific databases were used. It was found throughout the research that the public companies that have the control department increase their efficiency, improving the allocation of resources, detecting an increase of transparency in relation to the decisions of the public manager and also in relation to the rendering of accounts, enabling society to obtain information more clearly and objectively. We conclude that public sector controllership is relatively new, that it still needs to improve, and in many cases implementation still needs to be completed. Within the completed implementation cases, the results obtained are in line with the aspects pointed out in the literature, and an improvement in the management, transparency and accountability aspects can be perceived, which allows all interested parties access to consolidated information.
\end{abstract}

Keywords: Public sector control. Transparency. Accountability.

Data de submissão do artigo: 30/04/2019.

Data de aprovação do artigo: 22/08//2019.

DOI:

\title{
1 INTRODUÇÃO
}

A história brasileira recente é marcada por vários escândalos envolvendo os gestores públicos e a administração pública, tais como: corrupção, mau uso do dinheiro público, falta de controle, falta de transparência.

A questão da corrupção envolvendo gestores públicos não se faz presente apenas em países subdesenvolvidos ou em desenvolvimento, como no caso brasileiro, ela também é encontrada nos países desenvolvidos. Estudos contemporâneos apontam que esse tipo de problema é resultante da vulnerabilidade das instituições públicas que acarretam prejuízos em relação à transparência, a prestação de contas e até mesmo em relação ao controle (SODRÉ; ALVES, 2010).

O controle interno funciona como um instrumento da gestão pública que assegura informações gerenciais de qualidade, aos gestores públicos, proporcionando uma tomada de decisão mais eficiente e eficaz (SOARES, SCARPIN, 2015).

A administração pública possui a incumbência de gerir de forma eficiente os recursos públicos, voltando-se a atender os anseios da sociedade. Assim sendo, o gestor público é responsável pela administração e controle dos serviços públicos, planejamento, organização, direcionamento de todos os trabalhos desenvolvidos pelos órgãos públicos visando atingir 


\section{(11)}

suas metas e objetivos e, dessa forma, proporcionar bem estar à população (RODRIGUES; BETIM, 2014).

Segundo Silva (2013), a controladoria é o setor mais adequado dentro de um órgão para examinar o conteúdo das prestações de contas e os relatórios gerenciais que são enviados para os órgãos de controle externo.

Diante deste contexto, apresenta-se a seguinte questão problema: Quais as vantagens da utilização da Controladoria Pública para a gestão dos recursos municipais, para os gestores públicos e para a sociedade?

O objetivo dessa pesquisa é investigar como a controladoria governamental pode contribuir com uma gestão mais eficiente dos recursos públicos municipais, evidenciando suas vantagens para os gestores públicos e para a sociedade.

O tema tratado é atual e de grande relevância dentro do contexto brasileiro, uma vez que, os escândalos de corrupção e ingerência dos gestores públicos se multiplicam em todas as esferas da administração pública e os eleitores clamam por mudanças urgentes na maneira de gerir os recursos públicos.

No próximo título, será identificada a definição de controladoria, controladoria pública, suas principais funções, o profissional que está à frente da controladoria e qual o perfil exigido para este profissional, bem como a contextualização do cenário brasileiro.

\section{CONTROLADORIA}

A controladoria surgiu no Brasil na década de 1960, em razão do crescimento da industrialização brasileira. Nesse momento muitas indústrias de origem norte-americana se instalaram no país e trouxeram a cultura praticada em seu país. A controladoria, a princípio, estava presente nas grandes indústrias multinacionais. Com o aumento da competitividade, as empresas nacionais foram obrigadas a se reorganizar e se modernizar, neste momento, as técnicas modernas de controladoria foram incorporadas pelas empresas nacionais (SIQUEIRA; SOLTELINHO, 2001 apud SOUZA, 2015, p.44).

Mosimann e Fisch (1999) afirmam que a Controladoria é um conjunto de fundamentos e conhecimentos relativos à gestão econômica, podendo ser dividida em duas vertentes: Ela pode ser entendida como um órgão administrativo que possui missão, função e fundamentos norteadores determinados no modelo de gestão empresarial e, outra vertente, podendo ser vista como uma área do conhecimento humano que possui princípios, conceitos e métodos oriundos de outras áreas do conhecimento.

Padoveze (2016) entende que a contabilidade pode ser vista por dois enfoques distintos: o primeiro se concentra no controle econômico do patrimônio, bem como suas oscilações, enquanto o segundo se concentra no processo de comunicação e informação econômica. Com base nesse entendimento, o autor define "Controladoria" como uma unidade administrativa da organização que se utiliza do instrumental da Ciência Contábil.

Ainda segundo o autor Padoveze (2016, p. 3), cabe a controladoria "a responsabilidade de implantar, desenvolver, aplicar e coordenar todo o ferramental da Ciência Contábil dentro da empresa, nas suas mais diversas necessidades".

Figueiredo e Caggiano (2017, p. 11-12), diferente de Padoveze, entendem que a controladoria enquanto órgão de gestão empresarial não só utiliza as informações contábeis. Ela também é responsável pelo: "planejamento, controle, informação, contabilidade e supervisão de todas as atividades que impactam no desempenho empresarial". A controladoria vista como ramo do conhecimento busca eficiência e eficácia, além dos conceitos contábeis e 


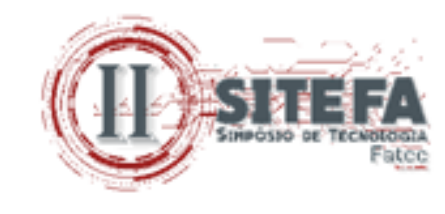

econômicos, nesse caso, existe a necessidade de interação com outras ciências, tais como: "Administração, Psicologia e Estatística".

Entretanto, o autor Barreto (2008) não compartilha do mesmo entendimento. Ele acredita que a controladoria não se limita apenas a um departamento e, sim em transformar o sistema contábil em uma grande estrutura, inclusive física e qualitativa, que suprem os gestores com informações relevantes para a tomada de decisão.

No mesmo sentido, os autores Oliveira, Peres Junior e Silva (2011) afirmam que para uma controladoria ser eficiente e eficaz, segundo os preceitos mais modernos de gestão, ela deve ser capaz de: sistematizar e reportar informações essenciais para os gestores, acompanhar os controles das diferentes atividades e monitorar o desempenho de outros departamentos, ser capaz de influenciar nas decisões dos gestores.

$\mathrm{Na}$ sequência, será apresentada a definição de controller, sua função e o perfil desejado para este tipo de profissional.

\subsection{O Controller}

O profissional que está à frente da controladoria é chamado de controller. Ele é responsável pela coordenação de um sistema de informação eficiente, que possui o objetivo de dar continuidade a empresa, direcionar as atividades para que as metas estabelecidas sejam atingidas e, se possível, sejam otimizadas (FIGUEIREDO; CAGGIANO, 2017).

A profissão do controller, no Brasil, surgiu em meados do século XIX, com a instalação de empresas multinacionais de origem norte-americana. Os profissionais dessas empresas vinham ao Brasil para capacitar os responsáveis pela área de controladoria visando "a implementação de um sistema de informação que fosse capaz de atender aos diferentes tipos de usuários da contabilidade, inclusive para manter um adequado sistema de controle sobre as operações das empresas relacionadas" (BEUREN, 2002, apud SOUZA, 2015, p. 44).

O controller deve apresentar o seguinte perfil: ser um profissional "multifuncional", apresentar conhecimentos profundos em: "Contabilidade e finanças, sistemas de informações gerenciais; tecnologia da informação, aspectos legais do negócio, visão empresarial, métodos quantitativos, processos informatizados da produção de bens e serviços" (OLIVEIRA; PERES JUNIOR; SILVA, 2011)

A seguir, será contextualizada a atuação da Controladoria dentro do órgão público.

\subsection{Controladoria Pública}

A Gestão Pública, segundo Brito (2016), se refere a um departamento administrativo, que se pauta em normas legais que orientam o seu funcionamento no sentido de gerar mais transparência e melhorar o desempenho dos gestores e funcionários públicos. A iminente necessidade de um aproveitamento mais eficiente dos recursos públicos brasileiros vem exigindo cada vez mais uma mudança estrutural, na gestão, e uma série de medidas legais que possam ajudar na melhoria do desempenho do setor.

No Brasil, desde 1964, por meio da Lei 4.320, em seu artigo 75, é exigido um controle nas organizações públicas. A Constituição Federal de 1988 veio corroborar com a exigência do controle interno em seus artigos 70 e 74, e um pouco mais tarde reforçou essa exigência de controle por meio da Lei Complementar 101 de 2000, conhecida como Lei de Responsabilidade Fiscal (DURIGON; DIEHL, 2013). 


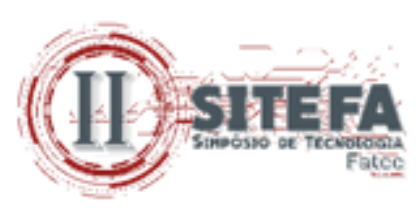

A Emenda Constitucional n. ${ }^{\circ} 19$ de 04 de junho de 1998 introduziu na administração pública brasileira o princípio da eficiência (SOARES; SCARPIN, 2015).

Castelo Neto (2009, p. 36) entende que o controle no contexto da administração pública "visa garantir a aplicação eficiente dos recursos públicos com o objetivo de atender aos anseios da sociedade por meio de programas e ações eficazes". Enquanto o controle é um instrumento de verificação da execução dos planos e metas traçados pela organização.

A Controladoria dentro do enquadramento da administração pública possui a atribuição de melhorar o desempenho econômico, otimizando a utilização dos recursos públicos gerando bem estar para toda sociedade (OLIVEIRA, 2010).

Silva (2013, p. 1) conceitua Controladoria Pública como:

Área que auxilia o gestor na tomada de decisão, na análise da eficiência, eficácia, economicidade e transparência de seus atos, avaliando a conduta nas rotinas internas, garantindo tranquilidade em sua passagem pela administração do órgão, proporcionando aos cidadãos garantia da boa gestão dos recursos públicos.

Na visão de Thompson e Jones (1986, apud DURIGON; DIEHL, 2013, p. 96) "a controladoria é voltada, principalmente, ao acompanhamento da efetivação orçamentária". O autor Atkinson et al. (2000 apud DURIGON; DIEHL, 2013, p. 96) acrescenta que "uma das ineficiências primárias do setor público é a dificuldade em criar e controlar medidas específicas para as exigências governamentais".

Sodré e Alves (2010) entendem que as ineficiências gerenciais do setor público ou de delitos praticados por gestores ou funcionários públicos contra o erário público, embora possam ser diferenciados quanto à intencionalidade dos agentes públicos ambos os casos proporcionam prejuízos para toda a sociedade.

A seguir, será realizada uma breve contextualização da corrupção presente no cenário brasileiro.

\subsubsection{Contextualização da corrupção presente no cenário brasileiro}

Segundo o Escritório das Nações Unidas sobre Drogas e Crime (UNODC), que executa ações que exprimem três convenções internacionais, são elas: controle de drogas, crime organizado transnacional e contra corrupção. A organização conceitua corrupção, como sendo abrangente e inclui "práticas de suborno, propina, fraude, apropriação indébita, nepotismo, extorsão, tráfico de influência, utilização de informação privilegiada para fins pessoais ou qualquer outro desvio de recursos por parte de um funcionário público" (UNODC, 2019).

Ainda segundo a mesma instituição, a corrupção é:

Um complexo fenômeno social, político e econômico que afeta todos os países do mundo. Em diferentes contextos, a corrupção prejudica as instituições democráticas, freia o desenvolvimento econômico e contribui para a instabilidade política. A corrupção corrói as bases das instituições democráticas, distorcendo processos eleitorais, minando o Estado de Direito e deslegitimando a burocracia. Isso causa o afastamento de investidores e desestimula a criação e o desenvolvimento de empresas no país, que não conseguem arcar com os 'custos' da corrupção (UNODC, 2019). 


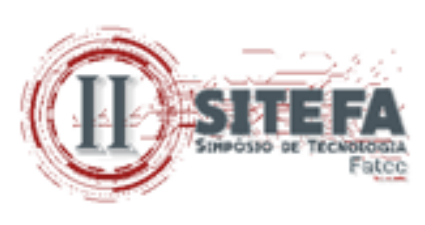

Segundo Rose-Ackerman (2002) as situações mais graves não são os subornos e propinas e sim o desvirtuamento advindo nas negociações executadas com recursos públicos que deixam reflexos negativos para a sociedade.

O portal Transparência Internacional desde 1995 realiza a medição da corrupção no mundo, por meio do Índice de Percepção da Corrupção (IPC), contando com escritórios distribuídos em 180 países. A instituição afirmou que em 2018, o Brasil apresentou o pior desempenho desde 2012 , caindo da $96^{\mathrm{a}}$ posição para $105^{\mathrm{a}}$ no ranking da Transparência Internacional, este índice reflete o índice de corrupção percebido no setor público (PORTAL TRANSPARÊNCIA INTERNACIONAL, 2019).

No próximo subtítulo, serão apresentados os tipos de controle exercidos pela administração pública.

\subsubsection{Controles}

Dentro da Administração Pública, existem dois tipos distintos de controle, segundo o autor Silva (2013) são eles:

O Controle interno: é aquele exercido pelo próprio órgão público, em relação aos seus atos praticados. Ele deverá munir o gestor de ferramentas para melhorar a utilização dos recursos arrecadados.

Ainda segundo Silva (2013, p. 6), o controle interno se dá em "cada setor ou área do órgão ao qual se destina a controlar algum procedimento interno: recursos humanos, almoxarifado, biblioteca, compras, contabilidade, jurídico, licitações, tesouraria etc.".

Controle Externo: Trata-se daquele que é colocado em prática, por meio de um órgão controlador, que não integra a organização do órgão público (SILVA, 2013).

O controle externo foi instituído pela Constituição Federal de 1988, artigo 71, inciso II, que estabelece que o Tribunal de Contas da União é responsável pelo julgamento das contas dos administradores públicos (BRASIL, 1988). As leis $\mathrm{n}^{\circ} \mathrm{s} 4.320 / 64$, regulamentada pelo Decreto-lei $n^{\circ}$. 200/67, Lei $n^{\circ}$. 6.223/75 e Lei ${ }^{\circ}$. 8.443/92 (Lei Orgânica do TCU) definem como o tribunal de Contas deverá atuar. A legislação supracitada estabelece que o controle externo dos Estados é exercido pelo Tribunal de Contas da União, do Distrito Federal é executado pelo Tribunal de Contas do Distrito Federal e dos Municípios é exercido pelo Tribunal de Contas do Município. Nota-se que o município de São Paulo criou o Tribunal de Contas do Município por meio da Lei Municipal $n^{\circ}$ 7.213, de 20 de novembro de 1.968, e mantido pela Emenda Constitucional $n^{\circ}$ 1, de 17 de outubro de 1969 (SÃO PAULO (SP), 1968), o Rio de Janeiro criou seu Tribunal de Contas do Município, por meio da Lei № 183 , de 23 de outubro de 1980 (RIO DE JANEIRO (RJ), 1980).

Sodré e Alves (2010) destacam que a falta de capacitação técnica existente nas instâncias governamentais impede a ocorrência de uma gestão eficiente, controlada e acrescenta ainda, que tal situação é mais evidente a nível municipal.

A seguir, serão apresentadas as vantagens apresentadas na literatura para a utilização da Controladoria Pública.

\subsection{Vantagens da utilização da controladoria pública}

Segundo Silva (2013), a Controladoria dentro do contexto público traz benefícios imediatos e, também, de longo prazo, tais como:

a) Padronização das atividades que os colaboradores dos órgãos deverão 


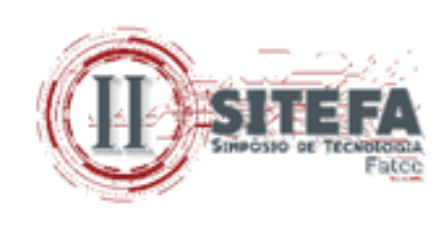

desempenhar;

b) Implementa a qualidade nos processos internos;

c) Atribui confiabilidade a todas as áreas do organismo público;

d) Assegura a continuidade dos trabalhos, mesmo com uma rotatividade alta de colaboradores;

e) Garante ao gestor a possibilidade de tomar uma decisão mais assertiva;

f) Centraliza o controle em especialistas, fato que garante mais eficiência;

g) Garante informações consistentes e de qualidade durante o processo de mudança da gestão.

Para Coelho (2006), a Controladoria Governamental possui sua missão ampliada em razão de não visar apenas um melhor desempenho econômico, como na iniciativa privada. $\mathrm{Na}$ esfera pública ela também se preocupa com a função social da execução de uma ação. Existe a necessidade de constatar se os anseios da sociedade foram totalmente satisfeitos com as medidas implementadas.

Na pesquisa realizada por Rodrigues e Betim (2014), junto ao Tribunal de Contas do Município de Ponta Grossa-PR, a Controladoria é considerada um departamento que serve de base para a tomada de decisão dos gestores públicos, contribuindo com uma administração mais eficaz. Os mesmos autores concluíram ainda que praticamente todas as funções descritas pela literatura ainda estão em fase de implementação pela Controladoria Geral do Município.

Soares e Scarpin $(2015$, p. 14) realizaram uma pesquisa baseada em entrevistas semiestruturadas aplicadas aos controladores municipais, visando avaliar a eficiência das práticas da controladoria municipal, tomando por base os controles orçamentários e financeiros praticados. A pesquisa abarcou 14 municípios que compõem a Associação dos Municípios do Médio Vale do Itajaí, localizado no estado de Santa Catarina. Os autores concluíram que "não existe um controle interno ideal, extremamente eficiente, mas que suas práticas devam sempre atender aos princípios da administração pública e, principalmente, ao exercício de uma permanente vigilância sobre os atos da gestão municipal". Em contrapartida em municípios menores onde existe uma escala hierárquica menor, "informalidade no relacionamento pessoal e menor volume de recursos e atividades, verificou-se que as práticas de controle interno são eficientes."

Os autores Sodré e Alves (2010) afirmam que:

\begin{abstract}
A inexistência de accountability ou controle efetivo, com consequente aplicação de penalidades, enfraquece o ideal democrático do governo, acirra o descrédito social em relação à atuação do governo e impacta na sua governabilidade. Além disso, ao favorecer inescrupulosos e aqueles que dispõem de maior rede de contatos, a corrupção deforma os papéis alocativos e redistributivos do Estado (SODRÉ; ALVES, 2010, p. 430).
\end{abstract}

Segundo o estudo sobre a Controladoria no setor público, de cunho teórico prático, realizado no município de Aquiraz-CE, pelos autores Daher, et al (2017, p. 394) foi constatado que a controladoria geral do município atua com "políticas de transparência pública, o controle das ouvidorias e a organização do acesso à informação, atividades que podem estimular o uso do controle social pela sociedade e servir como ferramenta de combate à corrupção". Os autores concluíram que apesar do estudo se restringir apenas a um município foi possível constatar que o Sistema de Controle Interno Municipal ainda precisa ser melhorado e sistematizado e, acredita-se que a literatura existente no meio acadêmico pode colaborar positivamente com este aspecto. 


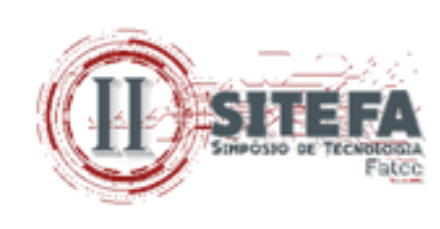

\section{METODOLOGIA}

Para responder ao problema de pesquisa: Quais as vantagens da utilização da Controladoria Pública para a gestão dos recursos municipais, para os gestores públicos e para a sociedade?

Utilizou-se a pesquisa bibliográfica, fontes secundárias de dados que segundo Lakatos e Marconi (2017) abarca toda bibliografia já publicada em relação ao tema da pesquisa. Foi utilizada também, a pesquisa documental envolvendo a apreciação do conteúdo de leis brasileiras pertinentes ao assunto tratado.

Quando aos fins da pesquisa, utilizou-se da investigação exploratória - descritiva. Exploratória com a finalidade aprofundar os conhecimentos acerca da adoção da Controladoria Pública e descritiva à medida que descreve o funcionamento da Controladoria Privada e Pública (VERGARA, 2011).

O presente trabalho de pesquisa apresenta cunho qualitativo, segundo Lakatos e Marconi (2017, p. 84), uma vez que "a finalidade da pesquisa científica não é apenas fazer um relatório ou descrição dos dados pesquisados empiricamente, mas também relatar o desenvolvimento interpretativo dos dados obtidos".

Para a análise dos dados coletados, por meio da pesquisa bibliográfica e documental, foram utilizados os métodos: Comparativo entre o que é realizado na prática e o que é descrito na teoria e a análise de conteúdo para interpretar os dados coletados.

\section{RESULTADOS E DISCUSSÃO}

A Controladoria entendida como órgão administrativo se fundamenta em determinados modelos de gestão. É responsável pelo planejamento, controle, informação, contabilidade e supervisão de todas as atividades que impactam no desempenho empresarial. Ela também pode ser vista como área do conhecimento humano que incorpora conceitos e métodos advindos de outras áreas do conhecimento, buscando a eficiência e eficácia.

A Controladoria não se limita a um departamento, mas sim, em transformar as informações contábeis, financeiras, econômicas, tributárias, em um grande banco de dados físico e qualitativo, visando melhorar a tomada de decisão. Ela é responsável por sistematizar e reportar as informações essenciais para que os gestores possam controlar o desempenho.

A controladoria pública tem suas funções aumentadas, uma vez que ela também é responsável pela função social dos seus atos.

O profissional que lidera a Controladoria, o Controller, é responsável por implementar e coordenar com eficiência o sistema de informação. O perfil desejado para este profissional é possuir habilidades nas áreas: contabilidade e finanças, sistemas de informações gerenciais, tecnologia da informação, aspectos legais do negócio, possuir uma visão empresarial, conhecer métodos quantitativos e processos informatizados da produção de bens e serviços.

No Brasil, existe uma estrutura legal que pauta o Sistema de Controle dividindo-o em controle externo e controle interno.

Existe o monitoramento e fiscalização, em relação à responsabilidade fiscal. A fiscalização e o controle prezam pela eficiência nas organizações públicas, visando melhorar o desempenho econômico e o bem estar social.

Existem ineficiências de ordem primárias que prejudicam o controle e, tanto os erros quanto os delitos praticados por funcionários públicos prejudicam toda a sociedade.

No ranking do Índice de Percepção da Corrupção entre 2012 e 2018 o Brasil caiu de 


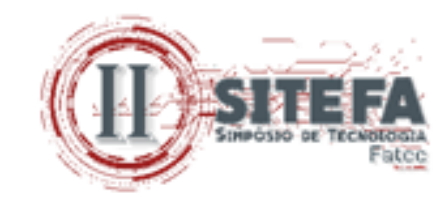

$96^{\circ}$ colocado para posição $105^{\circ}$, dentre 180 países participantes.

As instâncias governamentais apresentam falta de capacitação técnica e impede uma gestão eficiente.

As vantagens detectadas com a implantação da Controladoria são: padronização das atividades, aumento da qualidade nos processos internos; atribuição de maior confiabilidade ao sistema, preservação da continuidade dos trabalhos apesar da rotatividade, possibilidade de tomada de decisões mais assertivas, centralização do controle em especialistas e garantia de informações de qualidade.

\section{CONSIDERAÇÕES FINAIS}

O presente trabalho de pesquisa apresentou como objetivo investigar como a controladoria púbica pode contribuir com uma gestão mais eficiente dos recursos públicos municipais, evidenciando suas vantagens para os gestores públicos e toda a sociedade.

Conclui-se que a Controladoria vista como órgão administrativo ou como área do conhecimento humano, melhora o desempenho da organização.

A implementação do departamento de Controladoria Pública melhora a qualidade das informações passadas aos gestores e consequentemente melhora a tomada de decisões, trazendo eficácia e eficiência para a máquina pública e, em relação à sociedade proporciona bem estar.

Existe uma estrutura legal que norteia toda atividade pública visando gerar eficiência, transparência, e clareza na prestação de contas para toda sociedade, mas na prática ainda podem ser constatadas ineficiências que impedem alcançar o objetivo. Tal fato, deixa a população insatisfeita e pode ser constatado um aumento do índice da percepção de corrupção saltando de $96^{\circ}$, em 2012, para $105^{\circ}$ no ano de 2018.

Percebe-se ainda que em localidades distintas a Controladoria Pública ainda não foi totalmente implementada, portanto as vantagens oferecidas pela Controladoria pública tornam-se inconclusivas, pode-se apenas afirmar que a literatura científica fornece subsídios para a concluir a implementação da controladoria pública nesses municípios.

Nos municípios de pequeno porte, pode-se concluir que a Controladoria Púbica apresenta todas as vantagens descritas na teoria. Fato que nos leva a crer que a teoria é totalmente aplicável em condições empíricas, porém destaca-se que as informações ainda precisam ser mais bem sistematizadas.

Conclui-se, em linhas gerais, que a controladoria no setor público é algo relativamente novo, e que os resultados obtidos após sua implementação condizem com os aspectos apontados pela literatura, podendo ser percebida uma melhora nos quesitos gestão, transparência e prestação de contas, o que possibilita a todo e qualquer interessado ter acesso a informações consolidadas e fidedignas.

\section{REFERÊNCIAS}

BARRETO, M. da G. P. Controladoria na gestão: a relevância dos custos da qualidade. São Paulo: Saraiva, 2008.

BRASIL. Constituição da República Federativa do Brasil: promulgada em 5 de outubro de 1988. Diário Oficial da União, Poder Legislativo, Brasília, DF, 5 out. 1988. Anexo. p. 1. 
Disponível em: http://www.planalto.gov.br/ccivil_03/Constituicao/Constituicao.htm. Acesso em: 16 abr. 2019.

BRITO, S. M. de. A controladoria interna em âmbito municipal: estudo da realidade da prefeitura "x". TCC Curso de Especialização em Gestão Pública. Universidade Federal de Santa Maria. 2016.Disponível em: https://repositorio.ufsm.br/handle/1/15727. Acesso em: 26 abr. 2019.

CASTELO NETO, J. M. Controladoria como instrumento de otimização dos recursos públicos municipais. 2009. 120 f. Dissertação (Mestrado em Administração e Controladoria) - Universidade Federal do Ceará, Fortaleza, 2009.

COELHO, E. R. C. A Controladoria Governamental e o Controle da Aplicação de Recursos Públicos: um modelo de acompanhamento da execução orçamentária da despesa no município de Fortaleza. 2006. 140 f. Dissertação (Mestrado Profissional em Controladoria) - Universidade Federal do Ceará, Fortaleza, 2006.

DAHER, G. F.; MACHADO, M. V. V., CAVALCANTE, N. S. C.; MIRANDA, V. O de. Controladoria no setor público: um estudo teórico-prático no município de Aquiraz-CE. Revista Controle: Doutrinas e artigos, v. 15, n. 1, p. 367-397, 2017.

DURIGON, A. R.; DIEHL, C. A. Controladoria no setor público: uma análise dos artigos publicados no congresso USP de controladoria e contabilidade-período de 2001 a 2011. Contabilidade Vista \& Revista, v. 24, n. 2, p. 91-109, 2013.

FIGUEIREDO, S.; CAGGIANO, P. C. Controladoria: teoria e prática. 5. ed. São Paulo: Atlas, 2017.

LAKATOS, E. M.; MARCONI, M. de A.. Metodologia Científica. 7. ed. São Paulo: Atlas, 2017.

MOSIMANN, C. P.; FISCH, S. Controladoria: seu papel na administração de empresas. 2. ed. São Paulo: Atlas, 1999.

OLIVEIRA, A. B. S. Controladoria governamental: governança e controle econômico na implantação das políticas públicas. São Paulo: Atlas, 2010.

OLIVEIRA, L. M. de; PEREZ JUNIOR, J. H. ; SILVA, C. A. dos S. Controladoria estratégica. 7. ed. São Paulo: Atlas, 2011.

PADOVEZE, C.L. Controladoria básica. 3. ed. rev. e atual. São Paulo: Cengage Learning, 2016.

PORTAL TRANSPARÊNCIA INTERNACIONAL(PTI). Índice de Percepção da Corrupção 2018. Disponível em: http://ipc2018.transparenciainternacional.org.br/. Acesso em: 26 abr. 2019.

RIO DE JANEIRO. Lei N 183, de 23 de outubro de 1980. Cria o Tribunal de Contas do Município do Rio de Janeiro. Rio de Janeiro. 1980. Disponível em: http://www.tcm.rj.gov.br/ WEB/Site/Noticias.aspx?Categoria=25. Acesso em: 19 jul. 2019. 


\section{(II) SITEFA}

RODRIGUES, S. A.; BETIM, L. M. A controladoria em uma entidade pública: um estudo de caso na cidade de Ponta Grossa/Pr. Revista Organização Sistêmica, v. 5, n. 3, p. 110-127, 2014.

ROSE-ACKERMAN, S. A. Economia política da corrupção. In K. A. Elliot (Org.), A corrupção e a economia global. Brasília: UnB, 2002.

SÃO PAULO (SP). Lei Municipal $\mathbf{n}^{\mathbf{0}}$ 7.213, de 20 de novembro de 1.968. Cria o Tribunal de Contas do Município de São Paulo. 1968. Disponível em: www.tcm.sp.gov.br/legislacao /lorgtcm/Lei_n9167.pdf. Acesso em: 20 jul. 2019.

SILVA, E. F da. Controladoria na administra pública: manual prático para implantação, São Paulo: Atlas, 2013.

SOARES, M.; SCARPIN, J. E. Controle interno na administração pública: avaliando sua eficiência na gestão municipal. Revista de Ciências Jurídicas, v. 14, n. 1, 2015.

SODRÉ, A. C. de A.; ALVES, M. F. C. Relação entre emendas parlamentares e corrupção municipal no Brasil: estudo dos relatórios do programa de fiscalização da Controladoria-Geral da União. RAC-Revista de Administração Contemporânea, v. 14, n. 3, 2010.

SOUZA, C. T. D. de. A evolução da Controladoria: Um estudo no Brasil. Dissertação de Mestrado Profissional em Economia. Programa de Pós-Graduação em Economia da Faculdade de Ciências Econômicas da Universidade Federal do Rio Grande do Sul (UFRGS), 2015.Disponível em: https://www.lume.ufrgs.br/handle/10183/149351. Acesso em: 26 abr. 2019.

UNITED NATIONS OFFICE ON DRUGS AND CRIME (UNODC). UNODC e Corrupção. Disponível em: https://www.unodc.org/lpo-brazil/pt/corrupcao/index.html. Acesso em: 26 abr. 2019.

VERGARA, S.C. Projetos e relatórios de pesquisa em Administração. 13. ed. São Paulo: Atlas, 2011. 